\title{
Impacto de los medios de comunicación de masas sobre la opinión pública: ¿sobre los peligros de la adolescencia?*
}

\section{Impact of mass media over public opinion: about the dangers and prejudices of being adolescents?}

\author{
Eduardo Sandoval Obando* \\ Universidad Austral de Chile \\ Recibido: 2 de septiembre de 2014 \\ Revisado: 30 de noviembre de 2014 \\ Aceptado: 1 de febrero de 2015
}

\section{Resumen}

Este trabajo buscó reflexionar en torno al tratamiento noticioso que se le brinda, a los episodios de infracción de ley cometidos por adolescentes en Valdivia. Por consiguiente, se procedió al análisis del discurso (Van Dijk, 1990), desde una lógica interpretativa con énfasis en la macroestructura semántica con que se construye y describe la noticia. Dicho análisis nos posibilitó observar que las noticias en que aparecen vinculados jóvenes, expresan un discurso sensacionalista y estigmatizador, que fomenta y perpetúa la reproducción de estereotipos asociados a la adolescencia, caracterizada por la agresividad y la violencia, la transgresión permanente de las normas y el uso de armas para intimidar a otros, como factores explicativos de la conducta delictual. Finalmente, el trabajo refleja el impacto que provocan los medios de comunicación, sobre la opinión pública, fragmentando al sujeto producto de los prejuicios construidos en torno a la adolescencia.

Palabras clave: adolescencia, adolescente infractor de ley, medios de comunicación de masas, análisis del discurso. 


\section{Abstract}

This work sought to reflect on the news coverage that is offered, to episodes of violation of law committed by teenagers in Valdivia. Therefore, we proceeded to discourse analysis (Van Dijk, 1990), from a logical interpretative, emphasizing the semantic macro that is built and describes the news.

This analysis allowed us to observe that the news linked to young express a sensationalistic and stigmatizing discourse that promotes and perpetuates the reproduction of stereotypes associated with adolescence, characterized by aggression and violence, ongoing breach of the rules and use weapons to intimidate others, as explanatory factors for criminal behavior. Finally, the work reflects the impact caused by mass media and the fragmenting to the person constructed around the adolescence prejudices.

Keywords: Adolescence, adolescent offenders of law, mass media, discourse analysis

\section{Introducción}

La adolescencia como etapa evolutiva ha sido una temática de interés para las ciencias sociales y humanidades en general, producto de la multiplicidad de factores que intervienen en esta fase del desarrollo, que movilizan al adolescente a un estado de profunda ambivalencia frente a las normas impuestas por la sociedad, los cuestionamientos progresivos a los mandatos parentales y su vinculación al grupo de pares en la permanente búsqueda y definición de su identidad.

En lo particular, las investigaciones se han ocupado de los grupos de jóvenes cuyos comportamientos y actitudes se apartan significativamente de las normas socialmente impuestas, evaluándolos como preocupantes y socialmente disruptivos (subculturas juveniles: punk, raperos, barras bravas de equipos de fútbol, etc.), o se han interesado por generar modelos explicativos, desde una mirada adulto-céntrica, que describe fragmentariamente los enormes procesos y transformaciones que vive un joven en los tiempos actuales.

Gran parte de los estudios emergen desde perspectivas cartesianas, basados en cuestionarios y encuestas estructuradas que se ocupan 'objetivamente' de los aspectos reseñables de la vida juvenil: familia, estudios, ocio, actitudes, costumbres, religión, vivienda, asociación a pares, etc., con diferente énfasis, según los intereses del organismo que encarga el estudio.

No es causa de asombro el que una parte importante de estos estudios gire en torno a las actitudes de los jóvenes, en un intento por conocer lo que piensan, y así saber si están en condiciones de adquirir las responsabilidades y funciones propias de la adultez (es decir, integrarse a la sociedad como seres productivos). De esta manera, aquel que no se adscriba al canon social imperante, el Estado responderá con una intervención normativa, ejemplificadora y jurídicamente adecuada, para validar los mecanismos de control social existentes en la sociedad actual.

Los factores que inciden en este escenario pueden ser de distinta naturaleza y alcance, pero la adolescencia, como área de frontera para las ciencias sociales, representa una complejidad elevada, producto del proceso de constitución y diferenciación progresivo que experimenta el sujeto. De ahí que la tendencia general de las investigaciones sobre juventud en Chile haya perpetuado (intencionalmente o no), según Aguilera (2009), miradas disciplinarias restringidas y superficiales en torno al fenómeno investigado, algo que sin duda está vinculado con la nula inserción institucional de estas perspectivas en el ámbito académico. 
De igual manera algunos investigadores solo abordan coyunturalmente la adolescencia, dado que no representa un área debidamente valorada en la industria académica, y merman la construcción de bases sólidas para la formación de aquellos que tienen vínculos permanentes con estos jóvenes, tal como ocurre en el abordaje de los adolescentes infractores de ley. Al respecto, el mundo académico y diversos segmentos de la sociedad desconocen las problemáticas que los aquejan, así como las políticas públicas diseñadas para su abordaje, intervención y reinserción social efectiva.

Se observa también una falta de claridad, vacío e inapropiada sistematización de los estudios e investigaciones realizadas en Chile durante la última década en torno a la adolescencia (Valenzuela, 1984) y las diversas problemáticas que surgen en esta etapa. Al contrario, estos espacios se llenan por los procesos emergentes de significación que se desprenden del abordaje discursivo de los medios de comunicación, como constructores de sentidos y modeladores de la opinión pública.

Dicho lo anterior, este trabajo centró su mirada sobre las relaciones que se establecen entre los sistemas sociales y la opinión pública, a través del análisis discursivo de los medios de comunicación de masas y los productos comunicativos (las noticias, por ejemplo), en tanto reflejo de los cambios que se producen en un determinado entorno sociocultural. La difusión que realizan los medios sobre determinada visión de los hechos termina por construir representaciones de la realidad que se ajusten a los intereses de las audiencias y del sistema imperante al que responden:

La noticia es una ventana al mundo [...] tiende a decirnos qué queremos saber, que necesitamos saber y qué deberíamos saber [...]. Pero, como todo marco que delinea un mundo, el marco de la noticia puede considerarse problemático. La visión a través de una ventana depende de si la ventana es grande o pequeña, si tiene muchos o pocos cristales, si el vidrio es opaco o claro, si la ventana da cara a una calle o a un patio. La escena que se despliega depende también de donde está uno, lejos o cerca, alargando el cuello hacia un costado o mirando recto hacia delante con los ojos paralelos a la pared en la que está colocada la ventana (Tuchman, 1983, p. 13).

La propuesta, entonces, fue analizar el tratamiento que los medios de comunicación masivo (en este caso, un portal de radio en línea) brindan a los escenarios de jóvenes involucrados en hechos delictuales en Valdivia (Región de Los Ríos), con el objetivo de generar un proceso de análisis y discusión respecto al manejo de la información que le permita al receptor mediático ${ }^{1}$ (sujeto activo en el uso de la información) dar un tratamiento proporcionado, ecuánime y pertinente de la información sobre este tipo de jóvenes y los hechos delictuales en los que participan. Simultáneamente, este estudio se interesó por conocer las representaciones existentes en torno a la adolescencia y los jóvenes que, desde los medios, se ponen a disposición de las audiencias (el lector y la sociedad en general), para explorar las visiones que se construyen sobre esta etapa evolutiva, y con las que los receptores juzgan, opinan o asumen estas realidades.

\subsection{Supuestos orientadores del trabajo}

La lógica que orientó esta experiencia investigativa emerge desde el siguiente supuesto:

Las noticias referidas a situaciones en que los adolescentes se vinculan a hechos delictuales adquieren una connotación negativa, estigmatizadora y perpetuadora de ciertos estereotipos acerca de la adolescencia (conducta inmadura, transgresión permanente de las normas, consumo abusivo de alcohol y drogas, etc.) como modelos explicativos de su conducta.

Dicho lo anterior, se realizó un análisis cualitativo del discurso ${ }^{2}$, considerando distintas estructuras y

1 En palabras de Van Dijk (2003), los receptores mediáticos son "usuarios de la información activos, y hasta cierto punto independientes, cuyas creencias se conforman estratégicamente y cambian debido a los múltiples procesos cognitivos, sociales y comunicativos, así como por diversas fuentes de influencia discursiva".

2 Según Iñiguez y Antaki (1994), un discurso es un conjunto de prácticas lingüísticas que mantienen y promueven ciertas relaciones sociales. Por lo tanto, su análisis consiste en estudiar cómo estas prácticas influyen en el presente manteniendo, transformando y/o perpetuando estas relaciones. 
dimensiones de análisis, sobre un corpus reducido de noticias (tres en total), extraídas de una conocida radioemisora ${ }^{3}$ local.

\section{Antecedentes conceptuales y teóricos}

\subsection{Coordenadas conceptuales en torno a la adolescencia}

La adolescencia es aquella etapa del ciclo vital en que se produce la transición de la infancia a la adultez, y donde cada joven experimenta una amplia variedad de cambios corporales (aparición y desarrollo de caracteres sexuales secundarios, por ejemplo) y psicológicos (establecimiento del pensamiento lógico-abstracto, búsqueda y definición de la identidad, vinculación a pares, forma en que el joven evalúa y se relaciona con su entorno, etc.), entre otros. Por ende, esta etapa se vivencia como un periodo extenso y complejo, que abarca entre los 10 y los 20 años (Organización Mundial de la Salud, 2013).

No obstante, para efectos de este artículo, la mirada se centra en la adolescencia media, que comprende entre los 15 y los 20 años, etapa en la que mayoritariamente el joven se vincula a la comisión de delitos como parte de su desarrollo y búsqueda de identidad (Hogg y Vaughan, 2002), segmento etario comúnmente citado por los medios de comunicación.

\subsection{El delincuente situado en ¿la peligrosa adolescencia?}

Diversas investigaciones constatan que parte importante de la delincuencia común es cometida por jóvenes pertenecientes al rango etario descrito anteriormente. De manera superficial, se cree que aquellos vinculados a episodios de infracción

3 La Radio Bío-Bío es una estación de radio chilena, oriunda de la ciudad de Concepción. Se destaca por combinar noticias, música y deportes. Actualmente se le considera como la radio más escuchada en Concepción, y posee 42 estaciones de Arica a Punta Arenas. Cuenta además con su sitio web desde 2009, con el cual dio un giro hacia la publicación directa de noticias. Hoy en día es uno de los sitios de noticias más visitados del país, con 12,5 millones de visitas registradas durante julio de 2013. de la ley cometen tales acciones de forma intencional por simple maldad, por lo que merecen ser castigados. Más aún, se suele establecer una relación lineal entre delincuencia, juventud y deprivación sociocultural (pobreza, consumo abusivo de alcohol y drogas, inmadurez, disfuncionalidad familiar, contextos vulnerados, etc.), por lo que medidas represivas y estigmatizadoras suelen contar con amplia popularidad y adherentes.

Pese a lo anterior, se cree que la delincuencia en Chile no opera como un fenómeno homogéneo. Al contrario, asume características diferenciales, según sea la pertenencia ecológica, el sexo y el nivel educacional de los sujetos involucrados en los delitos, entre otros factores. Hay una preocupación cada vez más creciente, por parte de distintas fuerzas y actores sociales, en términos de plantear que el delinquir no es una categoría propia, como si sus actores fueran malos por naturaleza, sino que aquí hay un fundamento sociocultural significativo, que de alguna manera hace que determinados personajes lleguen a situaciones extremas, como podría ser el violentar a otros y robar, por ejemplo.

\subsection{Los jóvenes que delinquen y su relación con los medios de comunicación}

Analizar y comprender los episodios de infracción de ley en que participan los adolescentes, desde los medios de comunicación, exige una definición de dicho fenómeno. Por consiguiente, la delincuencia se conceptualiza como aquel fenómeno de transgredir o cometer actos fuera de los estatutos legales impuestos por la sociedad (leyes). Otros la definen como el "fenómeno social constituido por el conjunto de infracciones, contra las normas fundamentales de convivencia, producidas en un tiempo y lugar determinados" (Herrero, 1997, pp. 359-365). Pero, ¿Qué es lo que hace que un joven delinca? ¿Qué representa el delito para estos jóvenes? ¿Qué rol le cabe a la sociedad en esta materia?

Frente a este interrogante, Sandoval (2012, p. 58; 2014b) plantea que pueden existir múltiples fundamentos para comprender estas conductas: un 
acto de rebeldía contra el sistema imperante, una forma de expresión, un medio para la relación con otros, un mecanismo de supervivencia, una necesidad personal de validación social frente a sus pares, una carencia afectiva significativa, o, simplemente, una consecuencia de nuestra actual forma de relacionarnos, impregnada de prejuicios y desigualdades.

Adicionalmente, surge la pregunta: ¿Qué rol le es propio a los medios de comunicación en el abordaje de estos eventos? La delincuencia juvenil, en cuanto hecho social, es un fenómeno complejo, que está conectado con una crisis de valores de nuestra propia cultura (sistema neoliberal, atravesado por el fenómeno de la globalización, que incentiva el individualismo, la competencia y el consumismo); rupturas familiares; pobreza; grupos vulnerados; bajos niveles de escolarización; y la creciente privatización del Estado, pero sin que todo este conjunto de factores explique totalmente el episodio de infracción a la ley.

Lo cierto es que en la adolescencia se experimentan desequilibrios sociales, que pueden o no ser superados, según los recursos personales con los que cuente cada sujeto, pero que fraguan "conductas delictivas como protesta a lo que él considera una injusticia; o como respuesta socialmente inadecuada, pero para él satisfactoria, a sus necesidades" (Bueno y Moya, 1998: p. 154).

Admitamos que las explicaciones causalistas solo nos permiten comprender la infracción de ley en los adolescentes, de manera parcelada y superficial. Por ello, y frente al incremento en la frecuencia con que ocurren estos hechos, a edades más tempranas, se podría pensar que los procesos de socialización ${ }^{4}$ están siendo menos efectivos que antes, al menos por dos razones: 1) la sociedad promueve cánones sociales ideales para todos por

$4 \quad$ Berger y Luckmann (1996) distinguen entre socialización primaria y socialización secundaria. La primera es aquella por la que el individuo atraviesa la niñez y se convierte en miembro de la sociedad. Por su parte, la segunda corresponde a cualquier proceso posterior que induce al individuo, ya socializado, a nuevos sectores del mundo objetivo de su sociedad, es decir, la internalización de submundos institucionales o basados en instituciones. Su alcance y su carácter se determinan por la complejidad de la división del trabajo y la distribución social del conocimiento. Los submundos internalizados en la socialización secundaria son realidades parciales que contrastan con el mundo de base adquirido en la socialización primaria. igual (guiados por el "deber ser", como: estudiar, obtener una profesión, tener familia, etc.); y 2) los adolescentes construyen sus propios intereses, normas, valores, creencias y potencialidades a lo largo de su trayectoria vital, con mayor convicción y autonomía (aunque sean opuestos a lo socialmente esperado), de manera que se produce una contradicción entre lo que realmente quiere el adolescente y lo que espera la sociedad de este.

\subsection{El discurso mediático: Función e impacto sobre la opinión pública}

Los medios de comunicación de masas ocupan un rol protagónico en nuestra sociedad; son una fuente de conocimiento, difusión y construcción de la realidad, que los sujetos utilizan para informarse y generar opinión respecto a diversas temáticas, tales como: política, educación, cultura, adolescencia, economía, etc. Es decir, gran parte de nuestras ideas y debates se basan mayoritariamente en una imagen sesgada e ideológicamente construida a partir de los medios de comunicación. Por ello, la reflexión sobre el papel de los medios en la reproducción de estereotipos y visiones fragmentarias de estas problemáticas adquiere valor, dado que no conocen realmente el fenómeno ni al sujeto involucrado (Sandoval, 2014a;), pesquisa que resulta clave para contribuir a la implementación de futuras intervenciones en torno a la reinserción social y la información fidedigna aportada por los medios de comunicación.

Se conjetura que "los medios de comunicación juegan un papel fundamental en la conformación de las cogniciones sociales del público general" (Van Dijk, 2003: p. 232). Esto quiere decir que cualesquiera que sean los efectos inmediatos de los mensajes mediáticos específicos sobre lectores particulares, y bajo circunstancias específicas, los medios de comunicación masivos y el tratamiento de las noticias generarán un determinado tipo de influencia e impacto sobre las cogniciones sociales del grupo que no se pueden descartar, puesto que se convierten en una fuente de opinión e interpretación relevante para los sujetos y el discurso público. 
En lo particular, y al igual que diversos sectores de nuestra sociedad (grupos minoritarios, niños y adolescentes, etc.), padecen de una profunda discriminación mediática, que coarta su protagonismo y participación en aspectos de la vida social. La voz de sus protagonistas no es tomada en cuenta en la construcción y difusión de las noticias, lo que dificulta su valoración como una fuente informativa relevante que está cargada de importantes vivencias, construidas desde su cotidianidad.

Ahora bien, es indudable que los medios de comunicación de masas son en la actualidad una de las instancias de socialización más importantes para las nuevas generaciones, al reconocer que tanto el papel de la escuela como el de la familia están siendo progresivamente desplazados por el fácil acceso a estos medios. Esto implica que los medios de comunicación adquieren inevitablemente un rol protagónico como fuente de conocimiento y de formación de opiniones.

Los episodios de infracción de ley cometidos por jóvenes exhiben un desconocimiento elevado por parte de la gente, quienes se alarman y exigen respuestas drásticas y punitivas por parte del gobierno de turno, para frenar esta problemática. En concordancia con Hess (1986), los delincuentes están definidos en la prensa por la anormalidad, la distancia, la locura, la imposibilidad de empatía. Estos discursos sociales pueden llegar a ser tan potentes, que en ocasiones se asumen, aun cuando puedan contradecir la realidad cotidiana, porque los medios son espacios poderosos de legitimación social.

Hall y Jefferson (2010), en sus notas sobre los medios y la cultura de control social, advierten una relación simbiótica entre aquellos, la cual implica la reproducción de las definiciones de los organismos encargados del orden y del control. Estas instituciones son las responsables, además, de construir y difundir las definiciones primarias sobre tales hechos, sus participantes, sus contextos y los medios de su reproducción.

En este sentido, se ha observado que las escenas noticiosas donde participan adolescentes vinculados a hechos delictuales tienen en común un conjunto de elementos, imágenes, acciones y ca- racterizaciones que permite describir y consolidar fragmentariamente la percepción de los medios y las representaciones de estas situaciones en las cogniciones socioculturales actuales.

Dicho de otro modo, existen jerarquías que ordenan la percepción de los medios. El rango etario, el nivel educacional y la identidad de género se erigen como los elementos prioritarios, entre otros. De igual manera, la adolescencia aparece vinculada a un proceso de cronologización de la vida donde la edad, el género y el nivel socioeconómico influyen en la eficacia de las trayectorias y de los dispositivos sociales en la conformación de sujetos deseables o no.

A lo anterior, se añaden elementos que describen algunas condiciones de vida de estos sujetos, como el lugar de procedencia (nominación del barrio), la conformación familiar (presencia o no de algún miembro de la familia, familia monoparental, familia ampliada, disfuncionalidad familiar, etc.), la orientación sexual (si tiene pareja o no, y si es visibilizada; heterosexual u homosexual) y el aspecto físico (vestimenta) corte de pelo, presencia de marcas reconocidas, etc.).

Estos elementos aparecen cuando aportan información sobre el delito, o suman un ingrediente a la estigmatización de la delincuencia juvenil (los jóvenes delinquen porque no respetan y desaprovechan las oportunidades que les brinda la sociedad; son sujetos peligrosos que debieran estar privados de libertad; los que delinquen son flojos y aprovechadores; delinquen porque les gusta el riesgo y aprovecharse de la gente que trabaja, etc.).

\subsection{Los medios de comunicación de masas: ¿del deseo de informar al mantenimiento del statu quo?}

Por lo expuesto al inicio, y en palabras de Van Dijk (2003, p. 277), es posible reconocer que las noticias muestran una tendencia marcada hacia la asociación de los adolescentes, minorías y sectores oprimidos con los problemas, conflictos, desviaciones e incluso amenazas a la sociedad, a la vez que otorgan una mayor cobertura a los hechos de violencia, 
drogas, riñas y conductas de riesgo que a hechos positivos o destacables. De esta manera, configuran y refuerzan diversos procesos de discriminación, estigmatización y segmentación social que contribuyen a la mantención del actual sistema.

Con el paso del tiempo, se ha ido instaurando desde los medios de comunicación masivos una visión de la adolescencia caracterizada por dos grandes imágenes contradictorias entre sí: una idealizada, a menudo en la publicidad (la juventud se presenta como valor, ya sea desde el punto de vista estético, de salud o de estilo de vida), y otra estigmatizada, a menudo en la ficción y en las fuentes de información (a través de la figura de personas egoístas, hedonistas, violentas, sin valores, rebeldes sin causa, etc.). La cobertura mediática de los jóvenes transita constantemente entre dos posiciones completamente opuestas: por un lado son representados como criminales; por el otro, como víctimas (Falchikov, 1986; Porteous y Colston, 1980).

En suma, parece evidenciarse que las formas de selección y tratamiento noticioso de los asuntos vinculados a jóvenes en conflicto con la justicia vienen a legitimar una visión de la adolescencia desde la perspectiva de las instituciones de control social y de los adultos. No es un secreto que así también lo perciben los propios jóvenes, demostrado en diversas investigaciones (Espín, 2002): no se ven reflejados ni identificados con los modelos que de ellos y de su mundo se ofrecen. Esto podría explicar la progresiva falta de interés que los jóvenes muestran por la información de los medios de comunicación tradicionales y el descontento popular que expresan hacia las formas de gobierno:

Los jóvenes no se identifican a sí mismos en las imágenes estereotipadas que ofrecen de ellos los medios de comunicación social [...]. La difusión de una versión sesgada, manipulada o incompleta de la realidad juvenil, contribuye a acentuar la marginación de los jóvenes, a reducir sus posibilidades de inserción crítica en la sociedad, y de ejercer un verdadero papel de fermento renovador. (Rodríguez, 1989)

Por consiguiente, somos testigos de que el tratamiento noticioso sobre los jóvenes sirve para man- tenerlos en una constante minimización de sus recursos y capacidades; la adolescencia aparece estrictamente subordinada al mundo adulto (donde prima la estabilidad, los acuerdos y el autocontrol) hasta que sean capaces de mostrar su madurez, responsabilidad y orientación hacia el trabajo, facilitando el logro de una autonomía social plena.

\section{Diseño metodológico}

La noticia opera como una selección limitada de acontecimientos y personajes en la que interviene un periodista $y$, por otra parte, el medio de comunicación masivo como institución. Por lo tanto, más allá de la pretendida objetividad, siempre se observarán huellas de la enunciación, que pueden rastrearse y que hacen evidente el lugar desde el cual se ha producido el enunciado. Interesan aquí las cogniciones sociales que construyen los sujetos a partir de un evento noticioso determinado.

Se recurrió a los aportes de Van Dijk (1990) para el análisis del discurso (siguiendo una lógica eminentemente interpretativa), los cuales explican cómo sus estructuras (en particular de las noticias periodísticas o discurso de los medios) se relacionan con los procesos cognitivos que intervienen tanto en su producción como su comprensión. Así, las operaciones mentales de los sujetos en la producción o comprensión de textos se insertan en lo que él llama la cognición social, la cual integra el sistema de modelos, estereotipos, valores y creencias que existen en la sociedad. De esta manera, la memoria sería el lugar desde el cual distintas representaciones entrarían en contacto y se condicionarían unas a otras, generando un impacto sobre la reproducción de ciertos estereotipos sociales.

\subsection{Ejes empleados durante el análisis del discurso mediático}

Siguiendo el planteamiento de Van Dijk, se proponen los siguientes niveles para analizar un texto, verbal o escrito:

1. Temas (o macroestructuras semánticas): organizan globalmente el significado del discurso. 
Puesto que tales temas con frecuencia representan la información más importante, pueden influenciar la organización de un modelo: las proposiciones relevantes serán colocadas en una posición más alta, en la jerarquía del modelo, que las proposiciones menos importantes (Van Dijk, 1991).

2. Esquemas discursivos (o superestructuras, esquemas textuales): organizan primariamente las categorías convencionales que definen la forma canónica de un discurso, y, por lo tanto, parecen menos relevantes para la construcción de modelos (Van Dijk, 1988).

3. Contextualización local: estos significados influencian la información local en los esquemas mentales (modelos, representaciones semánticas). Por esta razón, el conocimiento presupuesto o establecido en el discurso puede requerir que los receptores establezcan hechos o relaciones similares entre ellos.

4. Contextualización histórico-cultural: refiere a los antecedentes que originaron el problema; acciones y consecuencias de los protagonistas, etc.

5. El estilo: las estructuras léxicas y sintácticas de superficie son susceptibles de variar en función del contexto (Giles y Coupland, 1991).

6. Recursos retóricos: las metáforas, los eufemismos, etc. Al igual que los esquemas discursivos, no influencian directamente el significado. Más bien lo hacen resaltar o lo difuminan, y con ello también la importancia de los acontecimientos.

\subsection{Textos analizados}

Se procedió a la selección aleatoria de tres noticias publicadas en el sitio web de la Radio BíoBío Chile, por medio de su buscador (donde se escribieron las palabras joven y Valdivia para delimitar la búsqueda en la sección nacional), con un enfoque en los hechos en los cuales participaron adolescentes, y que, de algún modo, aluden a delitos ocurridos en la región de Los Ríos durante 2013.

La estructura básica de análisis observada en cada una de estas noticias fue la siguiente: titular central, fotografía, sección, tamaño (espacio utilizado en términos cuantitativos) y comentarios realizados por los lectores. En este punto adquiere importancia la dimensión connotativa, la cual remite a los sentidos agregados o secundarios, que pueden relacionarse o no con un signo en función del uso, el contexto, la experiencia de una comunidad o un individuo, o las circunstancias específicas; aspectos que deben ser abordados con cautela y en estricto apego al uso y contexto en que se generan.

\section{Análisis y discusión de resultados}

Para facilitar la comprensión de este trabajo, los análisis se presentan por medio de tablas y figuras, con énfasis en la macroestructura semántica (contextualización histórico-cultural, categorías léxicas ${ }^{5}$ empleadas, simbolismo de las fotografías utilizadas, comentarios de los lectores, etc.):

5 Son aquellas que poseen un carácter referencial (aluden a procesos, propiedades, acciones o entidades). Operan como un inventario abierto (no existe un número específico y limitado para estas unidades). Los sustantivos, los verbos y los adjetivos son representantes canónicos de este tipo de unidades léxicas. 
Tabla 1

Noticia: "Adolescente infractor de ley y reincidencia penal"

\begin{tabular}{|c|c|}
\hline Entrada & Joven - Valdivia. \\
\hline Titular & $\begin{array}{l}\text { Condenan a joven que asaltó servicentro y dijo que había sido víctima de secuestro en } \\
\text { Valdivia. }\end{array}$ \\
\hline Entradilla & $\begin{array}{l}\text { La Justicia condenó a un joven por asaltar el servicentro Copec, camino a Niebla en Val- } \\
\text { divia. El imputado, después de huir, llegó por sus propios medios al hospital, diciendo que } \\
\text { había sido víctima de un secuestro, para ocultar su participación en el robo. }\end{array}$ \\
\hline Fotografía & $\begin{array}{l}\text { Sala de audiencia en Tribunal Oral en lo Penal de Valdivia, donde se observa la presencia } \\
\text { de un juez; funcionarios de Gendarmería de Chile (encargados de la seguridad y control } \\
\text { de los imputados); abogados (Defensoría y Fiscalía) y el joven detenido (esposado y cabiz- } \\
\text { bajo). }\end{array}$ \\
\hline Observaciones & $\begin{array}{l}\text { Positivo: Se protege la identidad del joven detenido (en el contenido de la noticia y en la } \\
\text { fotografía principal, donde no se muestra su rostro), velando por la protección a sus dere- } \\
\text { chos como imputado y el resguardo a sus datos de identificación. Asimismo, se presenta la } \\
\text { noticia de manera específica y acotada, facilitando su comprensión y lectura. } \\
\text { Negativo: La noticia plantea explícitamente la necesidad de generar condenas inmediatas } \\
\text { frente a los delitos cometidos por adolescentes (eficacia de la Fiscalía por conseguir una } \\
\text { condena de doce años de cárcel), recalcando la peligrosidad con que actúan (recurriendo } \\
\text { al uso de armas, como un cuchillo); el engaño y la mentira, como medio para la justifica- } \\
\text { ción de sus actos (haber mentido e informado a la Policía que había sido secuestrado); la } \\
\text { reincidencia penal, como un problema social que el Servicio Nacional de Menores no logra } \\
\text { controlar o detener (puesto que el joven tenía antecedentes penales por robo con violen- } \\
\text { cia y robo con intimidación). Por otra parte, la noticia recalca el desinterés por estudiar } \\
\text { del involucrado (puesto que habría abandonado su mochila y útiles escolares en las inme- } \\
\text { diaciones del sector donde cometió el delito). Además, en ningún momento se presenta } \\
\text { la voz del protagonista (joven detenido) como una instancia que le permita explicar su } \\
\text { conducta o dar su versión de los hechos. }\end{array}$ \\
\hline $\begin{array}{l}\text { Contextualización } \\
\text { histórico-cultural }\end{array}$ & $\begin{array}{l}\text { A partir de los antecedentes básicos que aporta el periodista con base en un hecho no- } \\
\text { ticioso, se encuentra que, en su gran mayoría, hace una alusión superficial a las acciones } \\
\text { perpetradas por un joven y las consecuencias de sus actos, sin aportar información más } \\
\text { precisa respecto al contexto en que esta situación ocurrió (por ejemplo, ¿es cierto que el } \\
\text { joven pertenecía al CIP CRC Valdivia? ¿Qué tipo de intervención brindó el SENAME? ¿Qué } \\
\text { responsabilidades tiene el poder judicial frente a los jóvenes que se encuentran con bene- } \\
\text { ficios? ¿Qué pruebas existen para culpabilizar mediáticamente al involucrado? ¿Recibió una } \\
\text { legítima defensa por parte del Estado?, etc.). }\end{array}$ \\
\hline $\begin{array}{l}\text { Categorías léxicas } \\
\text { empleadas }\end{array}$ & Joven - asaltar - robo - intimidar - sustraer - huir - ocultar - violencia - condena. \\
\hline Enlace & $\begin{array}{l}\text { http://www.biobiochile.cl/2013/06/18/condenan-a-joven-que-asalto-servicentro-y-dijo- } \\
\text { que-habia-sido-victima-de-secuestro-en-valdivia.shtml }\end{array}$ \\
\hline
\end{tabular}

Fuente: elaboración propia adaptado de Van Dijk (1988; 1991) 
Tabla 2

Noticia: "Joven arriesga condena en régimen cerrado en Valdivia"

\begin{tabular}{|c|c|}
\hline Entrada & Joven - Valdivia. \\
\hline Titular & $\begin{array}{l}\text { Valdivia: Joven arriesga cinco años de internación en régimen cerrado en recinto del Se- } \\
\text { name. }\end{array}$ \\
\hline Entradilla & $\begin{array}{l}\text { Cinco años de internación en régimen cerrado en un recinto del Sename arriesga joven de } \\
18 \text { años que, cuando era menor, participó en un violento asalto a una familia en un domi- } \\
\text { cilio del sector Los Fundadores de Valdivia. }\end{array}$ \\
\hline Fotografía & $\begin{array}{l}\text { Fachada central del Tribunal de Garantía de Valdivia, revestido por una pintura clásica del } \\
\text { poder judicial (color gris). Al costado izquierdo de la imponente estructura, se observa el } \\
\text { Ministerio Público (representa la Fiscalía), y en ella flamean dos banderas chilenas. }\end{array}$ \\
\hline Observaciones & $\begin{array}{l}\text { Positivo: Al igual que en la noticia anteriormente descrita, se invisibiliza al joven acusado } \\
\text { del delito, y se opta por la presentación de una imagen neutral del poder judicial (arqui- } \\
\text { tectura imponente, como signo de la justicia y el poder), bajo un día soleado y despejado } \\
\text { (bastante atípico en Valdivia, considerando que el procedimiento judicial ocurre el } 31 \text { de } \\
\text { mayo 2013). Por otra parte, se menciona que el joven prestó declaración voluntaria a la } \\
\text { fiscal, reconociendo los hechos que se le imputan. } \\
\text { Negativo: La noticia reitera la importancia de asegurar un marco jurídico carcelario efi- } \\
\text { ciente que acabe con la comisión de delitos perpetrados por jóvenes. Se busca "dar el } \\
\text { ejemplo" con penas extensas de privación de libertad (cinco años de cárcel, solicitados } \\
\text { por la Fiscalía). Asimismo, se hace énfasis en la peligrosidad criminal del imputado, quien } \\
\text { de manera agresiva intimidó y violentó a un grupo familiar con armas de fuego en su propia } \\
\text { vivienda (ubicada en sector Los Fundadores), escudándose en su minoría de edad. }\end{array}$ \\
\hline $\begin{array}{l}\text { Contextualización } \\
\text { histórico cultural }\end{array}$ & $\begin{array}{l}\text { Vaga alusión periodística respecto a la participación específica del adolescente en los } \\
\text { hechos narrados, teniendo en cuenta que participaron otras tres personas, de las cuales } \\
\text { no se hace ningún tipo de referencia. Es decir, se refuerza periodísticamente la relación } \\
\text { adolescente, violencia y peligrosidad criminal. }\end{array}$ \\
\hline $\begin{array}{l}\text { Categorías léxicas } \\
\text { empleadas }\end{array}$ & Joven - violento - asalto - menor - armas de fuego - robar - huir - intimidación. \\
\hline Enlace & $\begin{array}{l}\text { http://www.biobiochile.cl/2013/05/31/valdivia-joven-arriesga-5-anos-de-internacion-en- } \\
\text { regimen-cerrado-en-recinto-del-sename.shtml }\end{array}$ \\
\hline
\end{tabular}

Fuente: elaboración propia adaptado de Van Dijk (1988; 1991) 
Tabla 3

Noticia: “Apelan a fallo condenatorio en Tribunal de Garantía Valdivia”

\begin{tabular}{ll}
\hline Entrada & Joven - Valdivia \\
\hline Titular & $\begin{array}{l}\text { Apelan a fallo que condenó a adolescente de } 14 \text { años por violación de dos mujeres en } \\
\text { Valdivia }\end{array}$ \\
\hline Entradilla & $\begin{array}{l}\text { En acuerdo quedó la resolución de la Corte de Apelaciones de Valdivia ante el recurso } \\
\text { presentado por la Defensoría Penal Pública, que busca absolver a un adolescente de } 14 \\
\text { años por uno de los dos delitos de violación a los que fue condenado en primera instancia. }\end{array}$ \\
\hline
\end{tabular}

Fotografía

Estrado típico utilizado por un juez dentro de un tribunal, además de la presencia de un papel (representando la sentencia que continuamente dicta, en su rol judicial) y el martillo, como símbolo de la autoridad, el respeto y el poder con los que cuenta al interior del Poder Judicial.

Observaciones Positivo: En esta noticia se repite el patrón visual descrito en el artículo anterior, a través de una imagen neutral (martillo como símbolo del poder judicial); el juez es el encargado de administrar la justicia y las condenas requeridas para aquellas situaciones en las cuales se produzca la caída de las normas. Adicionalmente, la noticia intenta demostrar y recalcar institucionalmente este poder del Estado, como un mecanismo necesario para controlar y neutralizar la comisión de delitos por parte de adolescentes. Se resguarda identidad del adolescente o cualquier tipo de información vinculada a su historia de vida. Negativo: Se observa una marcada tendencia a reiterar comunicacionalmente aquellas actividades negativas y de alta conflictividad en las que participa un adolescente (violación y agresión en contra de una mujer adulta; conducta transgresora repetida y sostenida en el tiempo, puesto que habría violado a otras dos mujeres, siguiendo los mismos patrones de actuación. Sin embargo, ninguno de estos hechos ha sido probado judicialmente a cabalidad), que atenta gravemente contra toda forma de vinculación prosocial. Por otra parte, este hecho noticioso adquiere una connotación social relevante en Valdivia, lo que evidencia la necesidad, por parte de los lectores (usuarios que comentan esta noticia en el sitio web), de exigir y proponer penas sancionatorias de larga duración para acabar con la "impunidad" que ostentan estos jóvenes.

Contextualización Hay una omisión o simplificación reiterada de información por parte del discurso periohistórico-cultural dístico, que perjudica notoriamente al adolescente descrito en el hecho noticioso. Se le culpabiliza arbitrariamente por la comisión de otros dos delitos similares ( los cuales no hay ninguna resolución judicial clara y oficial que lo responsabilice por tales hechos), hecho que instala y refuerza ciertos estereotipos respecto a la adolescencia. Este tipo de discursos vulnera garantías constitucionales básicas de todo ser humano, que indican que toda persona es inocente hasta que se demuestre lo contrario, garantía que en esta situación es desechada.

Categorías léxicas Adolescente - violación - condena - menor - atacar - violar - golpear - víctimas (mujeres) empleadas - persecutor - acusar.

Enlace http://www.biobiochile.cl/2013/08/14/apelan-a-fallo-que-condeno-a-adolescente-de14-por-violacion-de-dos-mujeres-en-valdivia.shtml

Fuente: elaboración propia adaptado de Van Dijk (1988; 1991)

\section{Comentarios finales}

En primer lugar, el discurso mediático construido con base en delitos donde participan jóvenes evidencia una propensión hacia la homogeneización de esta etapa vital y del sujeto implicado, reforzando los estereotipos asociados a esta fase del desarrollo ( los jóvenes son peligrosos, se vinculan a episodios reiterados de transgresión de normas, los adolescentes infractores reinciden penalmente, todo joven vinculado a un hecho delictual es culpable, exhiben conductas violentas en contra de otros, son un peligro para la sociedad, etc.), sin abordar e integrar adecuadamente el contexto (local o histórico-cultural, por ejemplo) en que estos hechos ocurren. 
Con esto, el discurso simplifica, oculta, e incluso minimiza aquellos antecedentes que contribuyen a construir una mirada neutral y fidedigna del problema al que apunta el artículo noticioso. En este sentido, se vuelve prioritario enmarcar las noticias en su contexto (por ejemplo, el grupo social al que pertenecen los jóvenes), para disminuir y desnaturalizar la amplia gama de prejuicios y cogniciones sociales erradas que despliegan y construyen las personas a partir de estas situaciones, demostrando la influencia que poseen los medios de comunicación en la transmisión de ciertas ideologías y el marco interpretativo de la realidad que perpetúa las desigualdades sociales.

En segundo lugar, esta experiencia de análisis cualitativo del discurso mediático exige como principio ético evitar culpabilizar al joven implicado en hechos delictuales, sin contar con los antecedentes suficientes (por parte del periodista y, con mayor razón, del lector), respetando el principio de inocencia (válido constitucionalmente en Chile), y facilitar el adecuado proceso judicial, donde se investigan estos hechos y determinan responsabilidades. En especial, se observa la necesidad de replantear, evitar o disminuir el uso de categorías léxicas peyorativas (énfasis retórico expresado en un léxico dramático, uso de hipérboles y otras figuras estilísticas), que generan pánico en la sociedad, puesto que maximizan negativamente la conducta de los adolescentes y reproducen los procesos de estigmatización sociocultural a los que recurrentemente se ven expuestos en los medios de comunicación.

En tercer lugar, este trabajo invita a la reflexión respecto a la forma en que actualmente se construye el discurso mediático frente a jóvenes vinculados a uno o más episodios de infracción de ley, puesto que, sin aparente intencionalidad, siguen reproduciendo y reforzando aquellas teorías reduccionistas sobre la adolescencia, como un estadio caracterizado por la impulsividad, el descontrol, la mantención de conductas de riesgo, la caída de las normas, etc., como argumento para que los estamentos públicos adopten un rol paternalista, punitivo y racional frente a estas problemáticas.

En otras palabras, las instituciones hablan, organizan y determinan qué tipo de conductas debe mostrar un joven (respetar las normas, estudiar, ser responsable, obtener una profesión, trabajar, etc.), y cuáles debe reprimir o neutralizar (por ejemplo, a través de las condenas judiciales que involucran la privación de libertad); cuáles son los problemas que afectan a los jóvenes y cómo deben resolverlos.

Este trabajo manifiesta cómo las instituciones del Estado (poder judicial) y el discurso mediático (prensa radial, televisión, etc.) mantienen el statu quo a través de una reproducción anacrónica de aquellos valores y creencias propios de la cultura dominante, priorizando temáticas relacionadas con ámbitos de conflicto, violencia y pobreza (Van Dijk, 2007); ocultando, y a veces disipando, la verdadera naturaleza de este tipo de fenómenos.

En cuarto lugar, y en vista del análisis discursivo realizado en torno a las noticias seleccionadas dentro de este trabajo, queda de manifiesto la forma en que el discurso mediático logra modelar la opinión pública (determinando quién merece ser escuchado y quiénes están resignados al silencio y la invisibilización), por medio de una amplia gama de recursos semánticos, léxicos y retóricos (entre otros), utilizados sagazmente por los periodistas y los medios de comunicación, para describir a los adolescentes como sujetos violentos y de alta peligrosidad, otorgándoles cobertura, así como subrayando y recalcando sus errores, cualidades negativas $y$ hechos vinculados a su reincidencia penal, favoreciendo las lógicas de poder (clases sociales dominantes).

Finalmente, y en palabras de McQuail (1991), "el discurso periodístico y, en general, el de los medios de comunicación de masas, produce, reproduce y distribuye el conocimiento que permite dar sentido a la experiencia y a las opiniones de las personas", influyendo en la visión de su pasado, presente y futuro. Se explicitó la función-sentido de los medios de comunicación en la reproducción y extensión de determinadas ideologías en la actualidad, lo cual demuestra la importancia de la realización de este tipo de trabajos, pues permiten desarrollar (al menos a escala local) una postura crítica en el análisis de los discursos públicos (incluyendo no solo el periodístico, sino también el académico, el publicitario, el histórico y el 
escolar, entre otros), como un foco relevante para la investigación lingüística ( $\mathrm{y}$, por ende, para las ciencias sociales y humanidades), para tensionar la perpetuación de ideologías que promueven la discriminación, la desigualdad y el racismo al que se ven expuestos los jóvenes en nuestra sociedad.

\section{Referencias}

Aguilera, O. (2009). Los estudios sobre juventud en Chile: Coordenadas para un estado del arte. Última Década, 17(31), 109-127.

Berger, P., y Luckmann, T. (1996). La construcción social de la realidad. Buenos Aires: Amorrortu.

Bueno, A., y Moya, J. (1998). La delincuencia juvenil como síntoma: Perspectivas de intervención psicosocial. Revistas Alternativas. Cuadernos de Trabajo Social (6), 151-159.

Espín, M. (2002). La imagen de los jóvenes en los medios de comunicación: De la noticia al espectáculo. En F. Rodríguez (Ed.), Comunicación y cultura juvenil. Barcelona: Ariel.

Falchikov, N. (1986). Images of adolescence: An investigation into the accuracy of the image of adolescence constructed by the British newspapers. Journal of Adolescence, 1(9): 167-80.

Giles, H., \& Coupland, N. (1991). Language: Contexts and consequences. Milton Keynes: Open University Press.

Hall, S., y Jefferson, T. (2010). Resistencia a través de rituales. Subculturas juveniles en la Gran Bretaña de la Posguerra (1. ${ }^{\mathrm{a}}$ Ed.). La Plata: Universidad Nacional de La Plata, Facultad de Periodismo y Comunicación Social; Observatorio de Jóvenes, Comunicación y Medios.

Herrero, C. (1997). Criminología (parte general y especial). Madrid: Dykinson.

Hess, H. (1986). La Criminalitá Come Mito Quotidiano. Dei deliti e delle pene, (2): 187-213.

Hogg, M., \& Vaughan, G. (2002). Social psychology (3. ${ }^{a}$ Ed.). Londres: Prentice Hall.
Iñiguez, L., y Antaki, C. (1994). El análisis del discurso en psicología social. Boletín de Psicología, (44): 57-75.

McQuail, D. (1991). Introducción a la teoría de la comunicación de masas. Barcelona: Paidós.

Organización Mundial de la Salud. (2013). Salud de los adolescentes. Recuperado el 28 de agosto de 2013 de http://www.who.int/topics/adolescent_health/es/

Porteous, M., \& Colston, N. (1980). How adolescents are reported in the British press. Journal of Adolescence, 3(3), 197-207.

Rodríguez, F. (1989). Comunicación y lenguaje juvenil. Madrid: Fundamentos.

Sandoval, E. (2012). Construcción sociohistórica de la propensión a aprender de los adolescentes infractores de ley (Tesis de maestría, Universidad Austral de Chile, Valdivia).

Sandoval, E. (2014a). Posibilidades educativas del adolescente infractor de la ley: Desafíos y proyecciones a partir de su propensión a aprender. Psicología Educativa, 20(1) 39-46.

Sandoval, E. (2014b). Propensión a aprender de los adolescentes infractores de ley: Reflexiones desde el enfoque biográfico. Polis, 13(37) 251-273.

Tuchman, G. (1983). La producción de la noticia. Barcelona: Gustavo Gili.

Valenzuela, E. (1984). La rebelión de los jóvenes. Santiago de Chile: Sur.

Van Dijk, T. (1988). News as discourse. Hillsdale: Lawrence Erlbaum.

Van Dijk, T. (1990). La noticia como discurso: Comprensión, estructura y producción de la información. Barcelona: Paidós.

Van Dijk, T. (1991). Racism and the press. Londres: Routledge.

Van Dijk, T. (2003). Racismo y discurso de las élites. Barcelona: Gedisa.

Van Dijk, T. (2007). Racismo y discurso en América latina. Barcelona: Gedisa 